\begin{tabular}{|c|l|}
\hline Title & A nalysis of minor vitamin E homologues in natural products \\
\hline Author(s) & Beppu, Fumiaki; Gotoh, Naohiro \\
\hline Citation & Journal of Berry Research, 11(4), 555-566 \\
\hline https:/doi.org/10.3233/1BR-210009 \\
\hline Issue Date & 2021-12-15 \\
\hline Doc URL & http://hdl.handle.net/2115/83828 \\
\hline Rights & The final publication is available at IOS Press through http://dx.doi.org/10.3233/BBR-210009 \\
\hline Type & article \\
\hline File Information & jbr-11-jbr210009.pdf \\
\hline
\end{tabular}

Instructions for use 


\title{
Review
}

\section{Analysis of minor vitamin E homologues in natural products}

\author{
Fumiaki Beppu ${ }^{\mathrm{a}, *}$ and Naohiro Gotoh ${ }^{\mathrm{b}}$ \\ ${ }^{a}$ Faculty of Fisheries Sciences, Hokkaido University, 3-1-1 Minato, Hakodate, Hokkaido, Japan \\ ${ }^{\mathrm{b}}$ Department of Food Science and Technology, Tokyo University of Marine Science and Technology, Minato-ku, \\ 4-5-7 Konan, Tokyo, Japan
}

Received 31 May 2021

Accepted 16 July 2021

Pre-press 7 September 2021

Published 15 December 2021

\begin{abstract}
Fruits and seeds are naturally rich in antioxidants, which provide protection against UV light and oxygen. Vitamin E is a typical antioxidant, and offers radical scavenging activity to prevent the oxidation of the polyunsaturated fatty acids in cell membranes, contribute to homeostasis, and support the biological functions of animals and plants. Tocopherol and tocotrienol are forms of vitamin $\mathrm{E}$ widely found in natural products. In addition, recent studies have demonstrated the existence of minor homologues, namely tocomonoenol and tocodienol. The characteristic physiological functions of vitamin $\mathrm{E}$ homologues are dependent on their structure. Consequently, the nutritional functionality of the minor homologues has attracted much research interest, which relies on highly accurate analytical methods. This review aimed to summarize the literature concerning the diversity of tocomonoenol and tocodienol, as well as reports on the various methods for their analysis and detection in different sample matrices. This paper is expected to contribute to future exploratory research and the functional evaluation of minor homologues.
\end{abstract}

Keywords: Tocochromanol, tocodienol, tocomonoenol, tocopherol, tocotrienol, vitamin E

\section{Introduction}

Vitamin E (VE) is a group of fat soluble compounds based on a chroman ring structure with a phytyl side chain. Eight homologues of VE commonly occur in natural products, and can be classified as four tocopherol (Toc) isomers with saturated phytyl side chains, and four tocotrienol (T3) isomers with unsaturated phytyl side chains containing three double bonds. These two groups have $\alpha-, \beta-, \gamma-$, and $\delta$-isomers with different numbers and positions of methyl groups in the chroman ring. $\alpha$-Toc is the most abundant of the eight homologues, and is often the focus of research regarding the health functionality of VE.

Clinical studies have demonstrated that the intake of $\alpha$-Toc is associated with health benefits such as lower risks of cancer [1], atherosclerosis [2, 3], and type 2 diabetes [4, 5]. Further, research regarding the relationship between the structure of VE and its functionality has increased in the last two decades. Consequently, $\gamma$ - and

\footnotetext{
${ }^{*}$ Corresponding author: Fumiaki Beppu, Faculty of Fisheries Sciences, Hokkaido University, 3-1-1 Minato, Hakodate, Hokkaido 0418611, Japan. Tel.: +81 13840 8804; Fax: +81 13840 8804; E-mail: fbeppu@ fish.hokudai.ac.jp.
} 
<smiles>[R2]c1c([R])c([R1])c2c(c1[R])CCC(C)(CCCC(C)CCCC(C)CCCC(C)C)O2</smiles><smiles>[R3]c1c([R])c(O)c2c(c1[R1])OC(C)(CCCC(C)CCCC(C)CCC=[W]C(C)C)CC2</smiles>

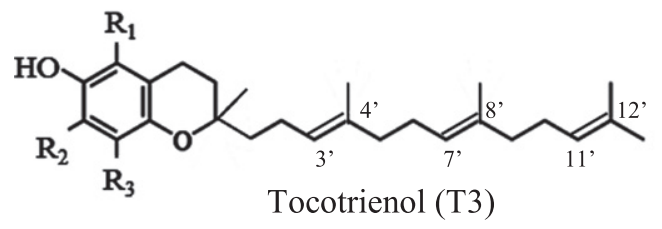<smiles>[R3]c1c([R])c(O)c2c(c1[R1])OC(C)(CCC=C(C)CCC(C)=CCCC(C)=[C]C(C)C)CC2</smiles>

$$
\begin{aligned}
& \alpha: \mathrm{R}_{1}, \mathrm{R}_{2}, \mathrm{R}_{3} \ldots \mathrm{CH}_{3} \\
& \beta: \mathrm{R}_{1}, \mathrm{R}_{3} \ldots \mathrm{CH}_{3}, \mathrm{R}_{2} \ldots \mathrm{H} \\
& \gamma: \mathrm{R}_{1} \ldots \mathrm{H}, \mathrm{R}_{2}, \mathrm{R}_{3} \ldots \mathrm{CH}_{3} \\
& \delta: \mathrm{R}_{1}, \mathrm{R}_{2} \ldots \mathrm{H}, \mathrm{R}_{3} \ldots \mathrm{CH}_{3}
\end{aligned}
$$

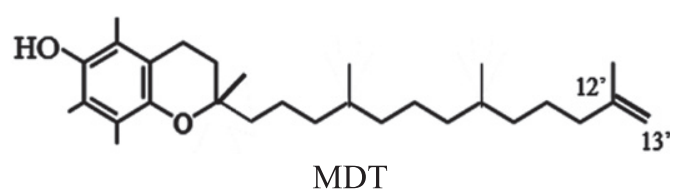

Fig. 1. Structure of minor homologues found in natural products. *: 3',11'- and 7',11'-T2 positional isomers have been identified.

$\delta$-Toc, and $\alpha$ - and $\gamma$-T3, which are abundant in palm oil and rice bran oil, respectively, have attracted more attention due to their potent bioactivities compared to $\alpha$-Toc [1, 6-8].

In response to the growing interest in the structure-dependent functionality of VE, quantitative analytical methods for VE homologues in food and biological samples have been developed and advanced. Specifically, developments in chromatographic and detection techniques have revealed the presence of tocomonoenol (T1) and tocodienol (T2) isomers as minor homologues in several plants and marine fish as described in the next section. Toc has a saturated side chain, while $\mathrm{T} 3$ has a side chain with three double bonds positioned at carbons 3'-4', 7'-8', and 11'-12'. Further, T1 and T2 have one and two double bonds, respectively (Fig. 1 and Table 1). As these compounds are minor constituents in VE, few studies have investigated their bioactive effects $[9,10]$. However, Toc and T3 exhibit characteristic structure-based activities and interesting functionalities are expected. Moreover, recent research have developed a new insight on the biological activity of Toc and T3 metabolite such as carboxychromanol and carboxyethyl hydroxychroman [11-14]. Health benefits of Toc and T3 may not solely depend on themselves but also gene regulation and homeostatic roles of substantial metabolites formed by cytochrome P450-catalyzed $\omega$-hydroxylation and oxidation. Molecular mechanisms and physiological importance of VE metabolites are currently under investigation in several laboratories. Investigating the physiological functions of T1 and T2 and their metabolites provides the novel findings on the chemical structure-based activities of VE homologues. Therefore, the exploratory research of natural products is expected to gain popularity in the near future to identify sources of these minor homologues.

This review aims to summarize the analytical methods used to study minor homologues of VE in a variety of natural products. These insights are expected to contribute to a more efficient search for sources of minor VE homologues.

\section{Minor homologues in natural products}

$\alpha-\mathrm{T} 1$ has a double bond at carbon 11'-12', and was first reported in palm oil in 1995 by Matsumoto et al. [15]. A VE-enriched fraction was obtained from crude palm oil via molecular distillation. In addition to $\alpha$-Toc 
Table 1

Minor homologues found in natural products

\begin{tabular}{|c|c|c|c|}
\hline Ref. & Minor homologues & Sample & Quantity \\
\hline \multirow[t]{3}{*}{ [15] } & \multirow[t]{3}{*}{$\alpha-\mathrm{T} 1$} & Palm oil deodorizer distillate & $12.8 \mu \mathrm{g} / \mathrm{g}$ \\
\hline & & Palmolein deodorizer distillate & $14.2 \mu \mathrm{g} / \mathrm{g}$ \\
\hline & & Rice bran ether extract & $7.2 \mu \mathrm{g} / \mathrm{g}$ \\
\hline \multirow[t]{2}{*}{ [16] } & \multirow[t]{2}{*}{$\alpha-\mathrm{T} 1$} & Palm oil & $40 \pm 5 \mathrm{ppm}$ \\
\hline & & Residual oil from palm pressed fiber & $430 \pm 6 \mathrm{ppm}$ \\
\hline [40] & $\alpha-\mathrm{T} 1$ & $\begin{array}{l}\text { Refined palm oil } \\
\text { (Crude, Degummed, bleached and } \\
\text { deodorized) }\end{array}$ & $29-40 \mathrm{mg} / \mathrm{kg}$ \\
\hline \multirow[t]{2}{*}{ [18] } & \multirow[t]{2}{*}{$\alpha-\mathrm{T} 1, \alpha-\mathrm{T} 2$} & $\mathrm{~T} 3$ rich fraction of palm oil & $\alpha-\mathrm{T} 1: 1.73-1.75 \mathrm{mg} / \mathrm{capsule}$ \\
\hline & & T3 soft gelatin capsules & $\alpha$-T2: $0.10-0.14 \mathrm{mg} / \mathrm{capsule}$ \\
\hline [19] & $3^{\prime}, 11^{\prime}-\alpha-\mathrm{T} 2,7^{\prime}, 11^{\prime}-\alpha-\mathrm{T} 2$ & $\begin{array}{l}\text { Countercurrent chromatography VE } \\
\text { fraction of palm oil }\end{array}$ & $\begin{array}{l}\sim 40 \mu \mathrm{g} / 100 \mathrm{~g} \text { palm oil (Sum total of } \mathrm{T} 2 \\
\text { isomers) }\end{array}$ \\
\hline$[22]$ & $\alpha-\mathrm{T} 1, \gamma-\mathrm{T} 1, \gamma-\mathrm{T} 2$ (suggested) & Pumpkin seed oil & $\begin{array}{l}\alpha-\mathrm{T} 1: 17.6 \pm 0.6 \mu \mathrm{g} / \mathrm{g}, \gamma-\mathrm{T} 1: \\
\quad 118.7 \pm 1.0 \mu \mathrm{g} / \mathrm{g}\end{array}$ \\
\hline$[21]$ & $\beta / \gamma-\mathrm{T} 1, \delta-\mathrm{T} 1$ & $\begin{array}{l}\text { Leaves of Kalanchoe daigremontiana } \\
\text { and Phaseolus coccineus }\end{array}$ & $\begin{array}{c}\beta / \gamma-\mathrm{T} 1: 1.7-3.1 \mu \mathrm{g} / \mathrm{g}, \delta-\mathrm{T} 1: \\
0.33-0.65 \mu \mathrm{g} / \mathrm{g}(\mathrm{FW})\end{array}$ \\
\hline$[20]$ & $\delta$-T1 & Kiwi (Actinidia chinensis) fruits & $\begin{array}{l}\text { Pulp: } 0.85 \pm 0.02 \mathrm{mg} / 100 \mathrm{~g} \text {, Peel: } \\
1.45 \pm 0.08 \mathrm{mg} / 100 \mathrm{~g}(\mathrm{FW})\end{array}$ \\
\hline$[23]$ & MDT & Chum salmon (Oncorhynchus keta) eggs & $7.6 \mathrm{mg}$ from $380 \mathrm{~g}$ chum salmon eggs \\
\hline$[24]$ & MDT & Fish eggs & $\begin{array}{l}\text { Chum salmon: } 35.8 \mathrm{nmol} / \mathrm{g} \text {, Masu } \\
\text { salmon: } 35.1 \mathrm{nmol} / \mathrm{g} \text {, } \\
\text { Cultured masu salmon: } 0.9 \mathrm{nmol} / \mathrm{g} \text {, } \\
\text { Flyingfish: } 0.2 \mathrm{nmol} / \mathrm{g}\end{array}$ \\
\hline
\end{tabular}

FW: Fresh weight.

and $\alpha$-T3, a compound with a maximum absorption at $292 \mathrm{~nm}$ was identified. The mass spectrum and ${ }^{1} \mathrm{H}$ NMR spectrum revealed an $\alpha$-type ring structure and a side chain with a double bond at 11'-12' carbon, thereby demonstrating the presence of $\alpha$-T1. The $\alpha$-T1 contents of commercially available palm oil, palm olein, and an ether extraction of rice bran were measured as $12.8,14.2$, and $7.2 \mu \mathrm{g} / \mathrm{g}$, respectively. $\mathrm{Ng}$ et al. [16] also reported the presence of $\alpha$-T1 in crude palm oil and the residual oil from palm pressed fiber at concentrations of $40 \pm 5 \mathrm{ppm}$ ( $3-4 \%$ of VE) and $430 \pm 6 \mathrm{ppm}$ (11\% of VE), respectively. Further, the presence of $\alpha-\mathrm{T} 2$ in palm olein was tentatively suggested by Mariani \& Bellan [17], and later confirmed by Gee et al. [18]. The VE content of a palm-based T3 soft gelatin capsule was investigated, which revealed that the $\alpha$-T2 and $\alpha$-T1 contents were 0.10 to 0.14 and 1.73 to $1.75 \mathrm{mg} /$ capsule, respectively. The study demonstrated that $\alpha-\mathrm{T} 2$ constitutes about $0.2 \%$ of the total VE in the T3-rich fraction from palm oil. A recent study by Muller et al. [19] identified two $\alpha-\mathrm{T} 2$ isomers with double bonds at carbon 3' -4 ' and 11' $-12^{\prime}$ or 7' -8 ' and 11' $-12^{\prime}$ in the VE fraction of palm oil enriched via countercurrent chromatography. The two isomers were present at equal concentrations with a sum total of $\sim 40 \mu \mathrm{g} / 100 \mathrm{~g}$ palm oil.

$\gamma$ - and $\delta$-type minor homologues have been found in various plants. For example, the content of $\delta$-T1 in the peel and pulp of kiwi fruits was reported as $0.85 \pm 0.02$ and $1.45 \pm 0.08 \mathrm{mg} / 100 \mathrm{~g}$ fresh weight [20]. Kruk et al. [21] identified $\beta / \gamma$-T1 and $\delta$-T1 in Kalanchoe daigremontiana and Phaseolus coccineus leaves of different ages, where young leaves had a relatively higher content of minor $\mathrm{T} 1(\gamma+\beta-\mathrm{T} 1=3.1 \pm 0.3, \delta-\mathrm{T} 1=0.65 \pm 0.20 \mu \mathrm{g} / \mathrm{g}$ fresh weight $)$ than old leaves $(\gamma+\beta-\mathrm{T} 1=1.7 \pm 0.1, \delta$-T1 $=0.33 \pm 0.03 \mu \mathrm{g} / \mathrm{g}$ fresh weight $)$. Further, Butinar et al. 
[22] identified $\alpha$-T1 $(118.7 \pm 1.0 \mu \mathrm{g} / \mathrm{g})$ and $\gamma$-T1 $(17.6 \pm 0.6 \mu \mathrm{g} / \mathrm{g})$ in Slovenian pumpkin seeds, and tentatively suggested presence of $\gamma$-T2.

A minor homologue characteristically present in marine organisms have been discovered. Yamamoto et al. [23] identified an isomeric $\alpha$-T1 called marine-derived tocopherol (MDT) in the lipophilic fraction of eggs from chum salmon (Oncorhynchus keta). The structure of this antioxidant was determined using gas chromatography-mass spectrometry (GC-MS), proton nuclear magnetic resonance $\left({ }^{1} \mathrm{H}\right.$ NMR), and carbon-13 nuclear magnetic resonance $\left({ }^{13} \mathrm{C}\right.$ NMR) analyses. The structure was $\alpha$-type T1 with a double bond at carbon 12 ' -13 ' in the side chain, unlike $\alpha$-T1 in oils from land plants (e.g., palm and rice) with a 11'-12' double bond. MDT was broadly present in the bodily tissues and eggs of marine fish, especially in cold water species [24]. Specifically, relatively high levels of MDT were reported in the eggs (35.1-37.7 nmol/g) and muscles $(1.7-5.2 \mathrm{nmol} / \mathrm{g})$ of chum salmon and masu salmon, while that of tropical fish such as flying fish, coral trout, and mangrove jack were only 0.2 to 3.1 and 0.01 to $0.13 \mathrm{nmol} / \mathrm{g}$, respectively. MDT has been detected in phytoplankton collected from the Oyashio ocean current, but the muscles and eggs of farmed masu salmon fed with a low MDT diet had very low levels of MDT. Thus, MDT is likely broadly distributed in marine fish via the food chain. Various processed seafoods also contain MDT, where a study on fish meat in processed foods in the United States and Japan by Gotoh et al. [25] revealed that canned sardines and tuna contained 42.8 to 156.4 and 6.7 to $42.7 \mathrm{mg} / 100 \mathrm{~g}$ MDT, respectively. Despite the exposure to high temperatures during deep-frying, cooked fish burgers based on Alaska pollock meat contained 41.4 to $41.9 \mathrm{mg} / 100 \mathrm{~g}$ MDT. This indicated that MDT has heat-resistant characteristics in food matrices.

Hammann et al. [26] reported the presence of $\alpha$-T1 and $\beta / \gamma-\mathrm{T} 1$ in cereals at concentrations of $\sim 1 \%$ to $2 \%$ relative to the corresponding Toc. Although the presence of minor homologues has only been confirmed in a limited number of plant and marine species, small amounts of these compounds are expected in a wide range of natural products. Moreover, minor homologues are likely transferred to human tissues via dietary sources. The presence and accumulation of MDT in human plasma [24] and animal tissue due to dietary MDT [27, 28] have been previously reported. The analysis of VE, including minor homologues, is required to examine their distribution in natural products, and their nutritional value in foods. In addition, further insights are required regarding in vivo metabolism and the role of minor VE homologues in health functions.

\section{Analytical method}

The detection of T1 and T2 in various biological samples, including seeds, fruit pulp and peel, and human plasma, has been achieved using procedures similar to those used for Toc and T3. Sample preparation is an important step in these methods, and includes organic solvent extraction, separation, and purification, after which chromatographic analysis can be conducted using various detectors. Due to the low abundance of T1 and T2, it is important to select an appropriate method to detect slight peaks, especially for concentration and chromatographic separation.

\subsection{Extraction, separation, and isolation}

The analysis of fruits, seeds, animal tissues, blood, and food products relies on reducing the matrix effect. This is based on efficient or selective extraction of the fraction containing the target compound. Edible fruits and peels with a high water content are usually dried or freeze-dried to increase the extraction efficiency. Specifically, Fiorentino et al. [20] and Butinar et al. [22] freeze-dried and oven-dried $\left(45^{\circ} \mathrm{C}\right.$ overnight $)$ plant leaves and fruit pulp prior to extraction, which enabled the detection of $\gamma$-T1 and $\delta$-T1.

Extraction is generally conducted using a suitable organic solvent to extract the lipophilic VE homologues from liquid and homogenized solid samples. Specifically, liquid-liquid extraction of total lipids based on the Bligh and Dyer method [29] is widely used, where various organic solvents (e.g., methanol, ethyl acetate, and 
$n$-hexane) and mixtures thereof may be used for VE extraction [30]. Selective extraction based on the polarity of organic solvents can reduce some matrices, such as proteins and other lipid compounds, which can simplify subsequent isolation. Minor homologues can be extracted along with Toc and T3 using $n$-hexane [21, 22], ether [15], ethanol [16] and ethyl acetate [20].

Saponification is a commonly used process to remove ester compounds from lipid samples via ester hydrolysis. The analysis of animal fat or plant crude oils relies on removal of the abundant triglycerides via saponification, after which lipophilic VE can be re-extracted as an unsaponified product. Potassium hydroxide has been previously used for the saponification prior to further concentration of $\alpha-\mathrm{T} 2$ in palm oil [19]. However, this procedure can damage and decompose the target compounds, thereby reducing the recovery rate. Thus, the concentration of aqueous alkali (e.g. potassium hydroxide), temperature, and reaction time must be controlled. A comparison of Toc extraction from human milk with or without saponification revealed that saponification leads to a higher recovery rate [31]. However, Nadal et al. [32] reported that a higher recovery can be achieved in small samples using a simplified method without saponification. Therefore, the necessity of saponification should be carefully considered.

Alternatively, distillation can be used to effectively concentrate the total VE fraction of oils. Matsumoto et al. [15] detected $\alpha$-T1 in lipid samples concentrated via molecular distillation (>90\% VE). Further, $\mathrm{Ng}$ et al. [16] reported that vacuum distillation after esterification and transesterification processing of crude palm oil allowed for the concentration of $\alpha$-T1 from $3 \%$ or $4 \%(40 \pm 5 \mathrm{ppm})$ to $11 \%(430 \pm 6 \mathrm{ppm})$.

Further concentration can be achieved by separating the minor homologue from the other lipid classes via solid phase extraction. Matsumoto et al. [15] purified $\alpha$-T1 using silica gel in a glass column. The VE-enriched lipid sample was developed with $n$-hexane/n-butyl ether $(99: 1,97: 3,95: 5,93: 7$, and 90:10 (v/v)), and the $\alpha$ T1-containing fraction eluted with $n$-hexane/2-propanol $(95: 5(\mathrm{v} / \mathrm{v}))$ was collected. $\alpha$-T1 was isolated using preparative high-performance liquid chromatography (HPLC) with methanol elution on a C18 column. Other studies on $\delta$-T1 [20] and $\gamma$-T1 [22] have used silica, $\mathrm{NH}_{2}$, or MP-alumina $\mathrm{N}$ columns, followed by reverse phase HPLC using C8 or C18 columns and normal phase HPLC using a silica column. Yamamoto et al. [23] charged salmon egg oil on silica gel, and MDT was eluted with $n$-hexane/2-propanol (25:1 (v/v)). Subsequent steps included re-extraction in methanol, solid-phase extraction with a $\mathrm{C} 18$ cartridge, and isolation with semipreparative reverse phase HPLC (C18). Overall, this procedure enabled the isolation of $7.6 \mathrm{mg}$ MDT from $380 \mathrm{~g}$ salmon egg.

A series of studies by Vetter Water's research group [19, 33-36] have demonstrated that countercurrent chromatography is effective for the preparative fractionation of VE homologues from fat and oil samples. Countercurrent chromatography involves constant stirring and separating the biphasic liquid system in a rotating coil. Specifically, the sample solution injected into the coil is separated due to the difference in partition coefficient to the biphasic solvent, and is eluted from the coil with the flowing mobile phase [37]. This technique was recently used by Muller et al. [19] to confirm the presence of two $\alpha$-T2 isomers, which comprised only $0.2 \%$ of the total $\mathrm{VE}$ in the T3-rich fraction from palm oil. Further, the presence of $\gamma$-T1 in the palm oil was confirmed, and the potential of $\beta$-T1 was proposed.

\subsection{Chromatographic analysis}

Colorimetric and fluorescence methods based on physicochemical properties have been used to quantify VE for a long time. However, GC and HPLC have recently become the preferred methods for separating and quantifying homologues. These highly accurate separation and quantification tools are also used in the quantitative analysis of minor homologues.

\subsubsection{Gas chromatography-mass spectrometry}

Many previous studies have conducted quantitative analysis of VE using GC methods (Table 2). Some studies derivatized minor homologues to increase the volatility and thermal stability of the samples [38, 39], while others analyzed the native form without derivatization [20, 23, 40]. Trimethylsilylation is a commonly used 
Table 2

Overview of analytical method using MS detector

\begin{tabular}{|c|c|c|c|c|}
\hline Analyzed homologues & Stationary, mobile phase & Detector & Molecular ion > Fragment ion $(\mathrm{m} / \mathrm{z})$ & Ref. \\
\hline$\alpha-\mathrm{T} 1$ & - & EI-MS & $428>165,205$ & [15] \\
\hline$\alpha-\mathrm{T} 1$ & - & MS & $428>165,205$ & [16] \\
\hline$\beta-\mathrm{T} 1, \gamma-\mathrm{T} 1, \delta-\mathrm{T} 1$ & - & APPI-MS & $\begin{array}{l}\gamma(\beta) \text {-Toc: } 414.4>151.0,191.0,205.0,231.1,245.1, \\
259.1,276.2,290.1,318.2,332.2,346.2,358.3,371.3 \\
385.4 \text { and } 399.4 \\
\delta \text {-T1: } 400.4>137,177,191,217,231.1,245.1,262.2 \\
276.2,318.2,332.2,344.2,358.2,371.3 \text { and } 385.3\end{array}$ & [21] \\
\hline \multicolumn{5}{|l|}{ (LC-connecting) } \\
\hline$\alpha-\mathrm{T} 1$ & $\mathrm{C} 30(3 \mu \mathrm{m}, 250 * 4.6 \mathrm{~mm}), \mathrm{MeOH}\left(\right.$ added $\left.\mathrm{AgClO}_{4}\right)$ & CIS-MS & $\begin{array}{l}\text { 535, } 537\left(\text { silver adduct ions }[\mathrm{M}+107]^{+} \text {and }\right. \\
\left.\qquad[\mathrm{M}+109]^{+}\right)\end{array}$ & [52] \\
\hline MDT & $\begin{array}{l}\text { Supelcosil } \mathrm{LC}-18 \text { column }(5 \mu \mathrm{m}, 250 * 4.6 \mathrm{~mm}) \text { in } \\
\text { tandem, } \mathrm{MeOH} / \mathrm{H}_{2} \mathrm{O}(50: 1)\end{array}$ & APCI-MS & $428>165,205$ & [25] \\
\hline \multicolumn{5}{|l|}{ (GC-connecting) } \\
\hline MDT & $\begin{array}{l}\text { OV-1 column }(1 \mathrm{~m} * 3 \mathrm{~mm} \text { i.d. }) \text { coated with } 1 \% \\
\text { Chromosorb W-HP }\end{array}$ & GC-EIMS & $428>165,205$ & [23] \\
\hline$\alpha-\mathrm{T} 1$ & HP5-MS column (95\% methyl, $5 \%$ phenyl polysiloxane) & EI-MS & $428>165,205$ & [40] \\
\hline$\delta$-T1 & $\begin{array}{l}\text { Zebron ZB-5MS column ( } 30 \mathrm{~m}, 0.25 \mathrm{~mm} \text { i.d., } 0.25 \mu \mathrm{m} \\
\text { film thicknes) }\end{array}$ & EI-MS & $\delta$-T1: $400>69,137,177$ & [20] \\
\hline & & & $\delta$-Toc: $402>43,137,177$ & \\
\hline & & & $\alpha$-Toc: $430>43,165,205$ & \\
\hline$\alpha-\mathrm{T} 1, \gamma-\mathrm{T} 1, \gamma-\mathrm{T} 2$ & DB5 column ( $20 \mathrm{~m}, 0.32 \mathrm{~mm}$ i.d., $0.1 \mu \mathrm{m}$ film thicknes) & MS scan, & $\begin{array}{l}\alpha-\mathrm{T} 1: 500 \\
\gamma-\mathrm{T} 1: 486 \text { (Silylated) }\end{array}$ & [22] \\
\hline$\alpha-\mathrm{T} 1, \beta / \gamma-\mathrm{T} 1$ & $\begin{array}{l}\text { DB-1HY column ( } 100 \% \text { dimethylpolysiloxane, } 15 \mathrm{~m} \text {, } \\
0.32 \mathrm{~mm} \text { i.d., } 0.1 \mu \mathrm{m} \text { film thickness })\end{array}$ & Q-TOF MS, & $\alpha-\mathrm{T} 1: 500.4050>237.1328$ & [26] \\
\hline $3^{\prime}, 11^{\prime}-\alpha-\mathrm{T} 2,7^{\prime}, 11^{\prime}-\alpha-\mathrm{T} 2$ & HP5-MS column (95\% methyl, $5 \%$ phenyl polysiloxane, & SIM, & $\begin{array}{l}\beta / \gamma-\mathrm{T} 1: 486.3894 \text { (Silylated) } \\
498>69,237,275,277 \text { (Silylated) }\end{array}$ & [19] \\
\hline
\end{tabular}

(SFC-connecting)

$\alpha-\mathrm{T} 1, \alpha-\mathrm{T} 2$ $30 \mathrm{~m}, 0.25 \mathrm{~mm}$ i.d., $0.25 \mu \mathrm{m}$ film thicknes)

Acquity ${ }^{\circledR} \mathrm{UPC} 2 \mathrm{BEH}^{\circledR}$ column $(1.7 \mu \mathrm{m}, 100 * 3 \mathrm{~mm})$, supercritical carbon dioxide/MeOH (99.5:0.5)

EI: Electron Impact, APPI: Atmospheric Pressure Photoionization Ionization, APCI: Atmospheric Pressure Chemical Ionization, CIS: Coordination Ionspray, Q-TOF: Quadrupole Time Of Flight. 
derivatization technique for GC-based VE detection, as high volatility of a substance is required. Butinar et al. [22] and Muller et al. [19,33] applied this approach to identify $\alpha$-T1 and $\gamma$-T1 in pumpkin seeds and $\alpha$-T2 in palm oil, respectively.

GC with packed and capillary column systems can both be used to analyze minor homologues, where capillary columns offer superior accuracy, separability, thermal stability, and sensitivity. VE is lipophilic, and separation of the structural isomers has been achieved using non-polar chromatographic stationary phases such as 5\%pheny1 95\%-methylsiloxane DB-5, HP5, and 5\%-phenyl 95\%-dimethylpolysiloxane ZB-5MS. The GC-separated tocochromanols are introduced into a mass spectrometer for structural identification and quantification. Previous studies have utilized electron ionization (EI) ion sources to identify novel minor VE homologues, such as $\gamma$-T1, $\delta$-T1, and $\alpha$-T2 isomers [19, 20, 22]. Minor homologues can be estimated by comparing side chain structure fragments with the corresponding spectra of Toc and T3. The diagnostic fragment ions of these homologues are summarized in Table 2. The EI spectrum of tocochromanol is related to the fragment derived from the respective chroman ring structures, namely mass to charge ratios $(\mathrm{m} / \mathrm{z})$ of 205 and 165 for $\alpha$-series, 191 and 151 for $\gamma / \beta$-series, and 177 and 137 for $\delta$-series. Yamamoto et al. [23] confirmed the presence of MDT based on EI fragments with a $m / z$ values of 165,205 , and molecular ion $m / z, 428$, which were 2 units less than $\alpha$-Toc. The presence of double bonds at the 11'-12' position in T1, T2 and T3 was verified based on the fragments related to the 3-methylbut-2-en-1-ylium cation. Fiorentino et al. [20] reported that an allylic fragment with a $\mathrm{m} / \mathrm{z}$ of 69 due to cleavage at 9'-10' was attributed to $\delta$-T1, and not $\delta$-Toc. Toc produces a fragment ion with a $\mathrm{m} / \mathrm{z}$ of 43 when the carbon chain is broken at carbon 11'-12', and fragmentation patterns for $\delta$-Toc, $\delta$-T1, and $\alpha$-Toc have been proposed. A similar fragment pattern was also observed when analyzed by trimethylsilylation, where the trimethylsilyl group led to a fragment with a $\mathrm{m} / \mathrm{z}$ of 73 and fragments with added trimethylsilyl groups appeared in the mass spectra.

Muller et al. [19] studied $\alpha-\mathrm{T} 2$ isomers in palm oil, and achieved good separation between $\alpha-\mathrm{T} 1$ and $\alpha-\mathrm{T} 2$, as well as between two $\alpha$-T2 isomers. The GC-MS system was equipped with a $30 \mathrm{~m}$ non-polar column (95\% methyl, 5\% phenyl polysiloxane, $0.25 \mathrm{~mm}$ internal diameter, $0.25 \mu \mathrm{m}$ film thickness) with a total run time of $35.8 \mathrm{~min}$. The $\alpha$-T2 isomers were identified based on a molecular ion with a $m / z$ of 498 and fragment with a $\mathrm{m} / z 237$ derived from the tropylium cation for $\alpha$-type chromanols. The MS spectra also revealed an isomer with a higher abundance at a $m / z$ of 277 , and another with a similar strength at a $m / z$ of 275 [19]. The researchers suggested that the two $\alpha \mathrm{T} 2$ isomers with two double bonds at positions 3' -4 ' and 11'-12', or at 7' -8 ' and 11' -12 ' in the GC-MS chromatogram could be assigned based on differences in their elution pattern, as isomers with double bonds closer to the tail end elute later in GC.

\subsubsection{High-performance liquid chromatography}

HPLC is the most useful analytical technique for separating and quantifying Toc, T3, and minor homologues, as derivatization steps are not required. This simplicity enables the analysis of tocochromanols in the free form, and thermal decomposition due to the derivatization reaction does not have to be considered. Many laboratories use HPLC methods to analyze trace amounts of minor homologues.

Normal phase HPLC techniques have been developed for the determination of Toc and T3 [41, 42]. Normal phase mode provides high separation of all Toc isomers, which elute in the order of $\alpha$-Toc, $\alpha$-T3, $\beta$-Toc, $\gamma$-Toc, $\beta$-T3, $\gamma-\mathrm{T} 3, \delta$ - Toc, and $\delta$-T3 due to the affinity with normal phase columns packed with silica or polar-bonded silica. Matsumoto et al. [15] and Gee et al. [18] demonstrated that $\alpha$-T1 and $\alpha$-T2 elute between $\alpha$-Toc and $\alpha$-T3 on silica gel chromatographic columns when a mixture of $n$-hexane, dioxane, and 2-propanol, or $n$-heptane and ethyl acetate is used as the mobile phase. Kruk et al. [21] achieved good separation between $\beta$-T1 and $\gamma$-T1 on a normal phase silica column eluted with $n$-hexane and tert-butyl methyl ether.

The use of reverse phase chromatography for VE analysis has gained recent popularity [43, 44], as it offers superior reproducibility and stability of chromatographic conditions compared to normal phase methods. The main principle of reverse phase chromatography is hydrophobic interactions between the compound and stationary phase, where the typical elution pattern is determined by the order of higher polarity, namely $\delta$-T3, $\beta / \gamma-\mathrm{T} 3, \alpha-$ 
T3, $\delta$-Toc, $\beta / \gamma$-Toc, and $\alpha$-Toc for a octadecylsilyl (ODS, C18) column. Polar mobile phases such as methanol and acetonitrile are typically used. Due to double bonds in the side chains, elution of T1 shifts earlier than the corresponding Toc, thus the peak of MDT co-elutes with $\gamma$-Toc during methanol elution on a C18 column. Consequently, minor compounds are not visibly separated. Analysis of $\alpha$-T1 and MDT in foods must consider coelution with $\gamma$-Toc and $\delta$-Toc, which are added to prevent oxidation. Water may be added to the mobile phase to change the polarity for improved separation. $\alpha-\mathrm{T} 1, \delta$-T1, and $\beta / \gamma-\mathrm{T} 1$ have been identified in palm oil using C18 chromatography with methanol/water (95:5, v/v) [15] and acetonitrile/methanol/water (72:8:1, v/v/v) [21] as mobile phases. Yamamoto et al. [24] achieved separation of $\delta$-Toc, $\alpha$-T1, $\gamma$-Toc, $\alpha$-Toc, and MDT in human plasma extracts using two analytical C18 columns in tandem and methanol/water (50:1, v/v) as the mobile phase. Further, complete separation among $\delta$-Toc, MDT, and $\gamma$-Toc has been achieved within a shorter total run time using a triacontyl (C30) column with methanol/acetonitrile (60:40, v/v) as the mobile phase [27].

The separation of $\gamma$ - and $\beta$-isomers has remained a challenge in reverse phase mode. However, recent downsizing of the column particle size and structural developments have enabled this separation. Some studies have reported that pentafluorophenyl (PFP)-bonded phases offer a unique selectivity due to various interactions, such as dipole-dipole, $\pi-\pi$, and hydrophobic interactions, which facilitate the separation of $\beta$ and $\gamma$-series isomers [45-47].

\subsubsection{Supercritical fluid chromatography}

Supercritical fluid chromatography (SFC) is a breakthrough chromatographic technique that uses carbon dioxide as the mobile phase. SFC is useful when separating structural and chiral isomers. A previous review [48] reported that SFC is useful for the analysis of lipophilic vitamins. Méjean et al. [49] achieved a good separation/detection of four Toc and $\alpha-, \gamma-, \delta$-T3 in soybean oil with a total run time of about 5 min on $\mathrm{NH}_{2}$ as stationary phase with carbon dioxide and ethanol as mobile phase. Further, Gee et al. [18] have demonstrated high separation of all isomers of Toc and T3 plus $\alpha$-T1 and $\alpha$-T2 in T3-rich fraction of palm oil using SFC based ultra-performance convergence chromatography $\left(\mathrm{UPC}^{2}\right)$. Comparison to HPLC on a $4.6 \mathrm{~mm} \times 250 \mathrm{~mm}$ Luna $5 \mu \mathrm{m}$ silica column with $n$-heptane/ethyl acetate (93:7) as the mobile phase, the clearer resolution among $\alpha$-tocochromanols was observed in $\mathrm{UPC}^{2}$ (mean resolution \pm SD between $\alpha$-Toc and $\alpha$-T1, $\alpha$-T1 and $\alpha$-T2, $\alpha$-T2 and $\alpha$-T3; HPLC: $1.72 \pm 0.04,1.38 \pm 0.14$ and $1.32 \pm 0.14, \mathrm{UPC}^{2}: 2.95 \pm 0.02,3.02 \pm 0.06$ and $3.06 \pm 0.04$ ). However, the disadvantage of this system is the limited options of detector and columns. As the high limits of detection (LOD) and limits of quantification (LOQ) of $\alpha$-Toc were observed (4.3 and $10.6 \mathrm{mg} / \mathrm{L}$, respectively), relatively higher noise level due to carbon dioxide with photodiode array detection is needed to be addressed.

\subsection{Detection}

VE minor homologues can be detected using ultraviolet (UV), fluorescent (FL), electrochemical detection (ECD), or MS detection. UV detectors have become the most popular due to easy use in routine analysis, and are used by many research groups. Toc, T3, and the minor homologues can be detected from 292 to $298 \mathrm{~nm}[16,18$, 40]. An FL detector has also been used for T1 detection at excitation wavelengths of 290 to $298 \mathrm{~nm}$ and emission wavelengths of 330 to $335 \mathrm{~nm}$ [15, 18, 21,22]. FL detection analyzes specific fluorescence wavelengths with specific excitation wavelengths and enables more selective and sensitive measurements than UV detection, as demonstrated by lower LOD and LOQ. Specifically, Cunha et al. [50] reported that the LOD values for $\alpha$-Toc were $0.0002 \mu \mathrm{g} / \mathrm{mL}$ for FL, $2.69 \mu \mathrm{g} / \mathrm{mL}$ for $\mathrm{UV}$, and $5.4 \mu \mathrm{g} / \mathrm{mL}$ for an evaporative light scattering detector.

ECDs offer highly sensitive and selective detection of compounds susceptible to electrochemical reactions (i.e., oxidation or reduction). ECD cannot be used for the purification step, as a supporting electrolyte must be added to the eluent for detection. However, VE with a low oxidative potential can be analyzed using a ECD with very high sensitivity, which is typically 10 to 20 times better than FL detection. Yamamoto et al. [23, 24] used 
ECD to identify MDT in salmon egg due to its redox potential. Further, an ECD analytical method by Gotoh et al. [25] had detection and quantification limits for MDT of $\sim 135$ and $\sim 446 \mathrm{pg}$, respectively.

MS detection for the analysis of VE has increased in popularity due to its high accuracy, sensitivity, and ability to simultaneously quantify multiple analytes. MS detection does not necessarily require complete chromatographic separation, which is highly beneficial. Both ESI and atmospheric pressure chemical ionization (APCI) techniques have been used in previous reports on VE analysis [30]. ESI in negative-ion mode have been used to detect $\alpha$-Toc and $\alpha$-T3 based on deprotonated molecular ions $[\mathrm{M}-\mathrm{H}]^{-}$with $\mathrm{m} / z$ values of 429 and 423 , respectively, along with the trimethyl-chromanol fragment ion at a $\mathrm{m} / \mathrm{z}$ of 163 . Positive-ion mode can detect $[\mathrm{M}+\mathrm{H}]^{+}$with $\mathrm{m} / \mathrm{z}$ of 431 and 425 for $\alpha$-Toc and $\alpha$-T3, respectively, along with a $m / z$ of 165 . Gee et al. [18] have identified the $\alpha-\mathrm{T} 2$ isomers by the protonated molecular ion $[\mathrm{M}+\mathrm{H}]^{+}$with an exact masses $m / z$ of 427.3576 and fragments $m / z$ of 205.1229 and 165.0916 using UPC $^{2}$-high-resolution mass spectrometry with APCI in positive-ion mode. Further, researchers assigned the double bond position at carbons $7^{\prime}-8^{\prime}$ and $11^{\prime}-12^{\prime}$ in the side chain with a characteristic fragments $\mathrm{m} / \mathrm{z}$ of 137.1330 and 69.0704 .

Recently, we proposed a liquid chromatography with tandem MS (LC-MS/MS) method for the quantification of $\alpha, \beta / \gamma$ and $\delta$-series Toc, T1, T2 and T3 in multiple reaction monitoring (MRM) mode [51]. To date, reference standards for T1 and T2 are not available. Hydrogenation was applied to pure T3 as a substrate to generate minor homologues, and the MRM parameters were established based on the mass spectrum of each compound. LC-MS/MS was performed with negative-ion mode ESI using reverse phase $\mathrm{C} 18$ columns. The MRM transitions $m / z$ of $427 / 163,425 / 163,413 / 149,411 / 149,399 / 135$ and 397/135 were verified to quantify $\alpha$-T1, $\beta / \gamma$-T1, $\delta$-T1, $\alpha-\mathrm{T} 2, \beta / \gamma-\mathrm{T} 2, \delta$-T2, respectively. Further, the method was used to detect tissue-specific accumulation of dietary $\mathrm{T} 1$ and T2 homologues in mice. The current method for analyzing VE in mice tissues is based on liquid-liquid extractions and LC-MS/MS with quantitative MRM parameters. Further research is required to distinguish the positional isomers of double bonds in the side chains, and the stereochemistry of minor homologues must be explored using chiral columns.

\section{Conclusions}

Novel VE homologues such as T1 and T2 have been reported in various biological samples, mainly including land plants, using GC and HPLC methods with various detectors. Improved concentration methods and chromatographic separation techniques have contributed to the detection of low-intensity peaks that were previously not visible. LC-MS/MS can be used to selectively detect multiple compounds simultaneously, which allows for the detection of minor homologues that co-elute with abundant homologues. Further, the $\alpha-, \beta / \gamma$ - and $\delta$-types of T1 and T2 can be quantified using MRM. Some reports have demonstrated that the $\beta$ - and $\gamma$-types can be separated using a PFP column. Thus, LC-MS/MS technology shows promise as the most effective and simple method for the comprehensive analysis of VE homologues. Future studies are expected to demonstrate the identification of the double bond positions and stereoisomers of T1 and T2 using column technology.

Palm oil and rice bran oil contain large proportions of $\gamma$ - and $\delta$-Toc, and $\alpha$ - and $\gamma$-T3, which have attracted attention due to their higher bioactivities than $\alpha$-Toc. Our previous cell experiments also revealed that MDT had a different effect on lipid metabolism and inflammatory response compared to $\alpha$ - and $\gamma$-Toc. The minor homologues have characteristic bioavailability and accumulation in mouse tissues. These results raised interest as a novel biofunctional material for T1 and T2 in natural products. Analysis of the distribution and profile of VE homologues also shows promise for investigating the dietary habits and food chain of animals, thereby contributing to the traceability of livestock meat and farmed fish. This review paper containing the current knowledge for the experimental data and methodological information on minor VE homologues will be helpful for further investigation of new homologues or distribution in natural plants and animals. 


\section{Acknowledgments}

This work was supported by the Japan Society for the Promotion of Science KAKENHI (Grant No. 18K14403 and No. 26850132). We would like to thank Editage (www.editage.jp) for English language editing.

\section{Conflicts of interest}

Given his role as Guest Editor of this issue, Fumiaki Beppu had no involvement in the peer-review of this article and has no access to information regarding its peer-review.

\section{References}

[1] Ju J, Picinich SC, Yang Z, Zhao Y, Suh N, Kong AN, et al. Cancer-preventive activities of tocopherols and tocotrienols. Carcinogenesis. 2010;31(4):533-42.

[2] Stampfer MJ, Hennekens CH, Manson JE, Colditz GA, Rosner B, Willett WC. Vitamin E consumption and the risk of coronary disease in women. N Engl J Med. 1993;328(20):1444-9.

[3] Glynn RJ, Ridker PM, Goldhaber SZ, Zee RY, Buring JE. Effects of random allocation to vitamin E supplementation on the occurrence of venous thromboembolism: report from the Women's Health Study. Circulation. 2007;116(13):1497-503.

[4] Upritchard JE, Sutherland WH, Mann JI. Effect of supplementation with tomato juice, vitamin E, and vitamin C on LDL oxidation and products of inflammatory activity in type 2 diabetes. Diabetes Care. 2000;23(6):733-8.

[5] van Tits LJ, Demacker PN, de Graaf J, Hak-Lemmers HL, Stalenhoef AF. alpha-tocopherol supplementation decreases production of superoxide and cytokines by leukocytes ex vivo in both normolipidemic and hypertriglyceridemic individuals. Am J Clin Nutr. 2000;71(2):458-64.

[6] Wong SK, Chin KY, Suhaimi FH, Ahmad F, Ima-Nirwana S. Vitamin E As a Potential Interventional Treatment for Metabolic Syndrome: Evidence from Animal and Human Studies. Front Pharmacol. 2017;8:444.

[7] Fang F, Kang Z, Wong C. Vitamin E tocotrienols improve insulin sensitivity through activating peroxisome proliferator-activated receptors. Mol Nutr Food Res. 2010;54(3):345-52.

[8] Wong WY, Ward LC, Fong CW, Yap WN, Brown L. Anti-inflammatory $\gamma$ - and $\delta$-tocotrienols improve cardiovascular, liver and metabolic function in diet-induced obese rats. Eur J Nutr. 2017;56(1):133-50.

[9] Fujisawa A, Dunlap WC, Yamamoto Y. Vitamin E protection in the biochemical adaptation of marine organisms to cold-water environments. Comp Biochem Physiol B Biochem Mol Biol. 2010;157(2):145-58.

[10] Beppu F, Aida Y, Kaneko M, Kasatani S, Aoki Y, Gotoh N. Functional evaluation of marine-derived tocopherol, a minor homolog of vitamin E, on adipocyte differentiation and inflammation using 3T3-L1 and RAW264.7 cells. Fish Sci. 2020;86(2):415-25.

[11] Schmolz L, Wallert M, Rozzino N, Cignarella A, Galli F, Glei M, et al. Structure-Function Relationship Studies In Vitro Reveal Distinct and Specific Effects of Long-Chain Metabolites of Vitamin E. Mol Nutr Food Res. 2017;61(12).

[12] Galli F, Azzi A, Birringer M, Cook-Mills JM, Eggersdorfer M, Frank J, et al. Vitamin E: Emerging aspects and new directions. Free Radic Biol Med. 2017;102:16-36.

[13] Jang Y, Park NY, Rostgaard-Hansen AL, Huang J, Jiang Q. Vitamin E metabolite 13'-carboxychromanols inhibit pro-inflammatory enzymes, induce apoptosis and autophagy in human cancer cells by modulating sphingolipids and suppress colon tumor development in mice. Free Radic Biol Med. 2016;95:190-9.

[14] Birringer M, Lorkowski S. Vitamin E: Regulatory role of metabolites. IUBMB life. 2019;71(4):479-86.

[15] Matsumoto A, Takahashi S, Nakano K, Kijima S. Identification of New Vitamin E in Plant Oil. Journal of Japan Oil Chemists' Society. 1995;44(8):593-7.

[16] $\mathrm{Ng} \mathrm{MH,} \mathrm{Choo} \mathrm{YM,} \mathrm{Ma} \mathrm{AN,} \mathrm{Chuah} \mathrm{CH,} \mathrm{Hashim} \mathrm{MA.} \mathrm{Separation} \mathrm{of} \mathrm{vitamin} \mathrm{E} \mathrm{(tocopherol,} \mathrm{tocotrienol,} \mathrm{and} \mathrm{tocomonoenol)} \mathrm{in} \mathrm{palm}$ oil. Lipids. 2004;39(10):1031-5.

[17] Mariani C, Bellan G. Presence of tocopherol derivatives in vegetable oils. Rivista Italiana Delle Sostanze Grasse. 1997;74:545-52.

[18] Gee PT, Liew CY, Thong MC, Gay MC. Vitamin E analysis by ultra-performance convergence chromatography and structural elucidation of novel alpha-tocodienol by high-resolution mass spectrometry. Food Chem. 2016;196:367-73.

[19] Muller M, Kropfl A, Vetter W. Identification of two alpha-tocodienol isomers in palm oil after countercurrent chromatographic enrichment. Anal Bioanal Chem. 2020;412(3):795-802. 
[20] Fiorentino A, Mastellone C, D’Abrosca B, Pacifico S, Scognamiglio M, Cefarelli G, et al. $\delta$-Tocomonoenol: A new vitamin E from kiwi (Actinidia chinensis) fruits. Food Chem. 2009;115(1):187-92.

[21] Kruk J, Pisarski A, Szymanska R. Novel vitamin E forms in leaves of Kalanchoe daigremontiana and Phaseolus coccineus. J Plant Physiol. 2011;168(17):2021-7.

[22] Butinar B, Bucar-Miklavcic M, Mariani C, Raspor P. New vitamin E isomers (gamma-tocomonoenol and alpha-tocomonoenol) in seeds, roasted seeds and roasted seed oil from the Slovenian pumpkin variety 'Slovenska golica'. Food Chem. 2011;128(2):505-12.

[23] Yamamoto Y, Maita N, Fujisawa A, Takashima J, Ishii Y, Dunlap WC. A new vitamin E (alpha-tocomonoenol) from eggs of the Pacific salmon Oncorhynchus keta. J Nat Prod. 1999;62(12):1685-7.

[24] Yamamoto Y, Fujisawa A, Hara A, Dunlap WC. An unusual vitamin E constituent (alpha-tocomonoenol) provides enhanced antioxidant protection in marine organisms adapted to cold-water environments. Proc Natl Acad Sci U S A. 2001;98(23):13144-8.

[25] Gotoh N, Mashimo D, Oka T, Sekiguchi K, Tange M, Watanabe H, et al. Analyses of marine-derived tocopherol in processed foods containing fish. Food Chem. 2011;129(2):279-83.

[26] Hammann S, Korf A, Bull ID, Hayen H, Cramp LJE. Lipid profiling and analytical discrimination of seven cereals using high temperature gas chromatography coupled to high resolution quadrupole time-of-flight mass spectrometry. Food Chem. 2019;282:27-35.

[27] Beppu F, Kondo H, Kasatani S, Aoki Y, Gotoh N. Quantitative Analysis of the Accumulation of Marine-derived Tocopherol in the Tissue of Mice Fed with Salmon Roe Oil Using HPLC-fluorescence. J Oleo Sci. 2018;67(3):283-8.

[28] Gotoh N, Watanabe H, Oka T, Mashimo D, Noguchi N, Hata K, et al. Dietary marine-derived tocopherol has a higher biological availability in mice relative to alpha-tocopherol. Lipids. 2009;44(2):133-43.

[29] Bligh EG, Dyer WJ. A rapid method of total lipid extraction and purification. Can J Biochem Physiol. 1959;37(8):911-7.

[30] Bartosińska E, Buszewska-Forajta M, Siluk D. GC-MS and LC-MS approaches for determination of tocopherols and tocotrienols in biological and food matrices. J Pharm Biomed Anal. 2016;127:156-69.

[31] Korchazhkina O, Jones E, Czauderna M, Spencer S, Kowalczyk J. HPLC with UV detection for measurement of vitamin E in human milk. Acta Chromatographica. 2005;16.

[32] Romeu-Nadal M, Morera-Pons S, Castellote AI, López-Sabater MC. Determination of $\gamma$ - and $\alpha$-tocopherols in human milk by a direct high-performance liquid chromatographic method with UV-vis detection and comparison with evaporative light scattering detection. J Chromatogr A. 2006;1114(1):132-7.

[33] Muller M, Hammann S, Vetter W. Countercurrent chromatographic isolation and purification of 11'-alpha-tocomonoenol from the vitamin E extract of palm oil. Food Chem. 2018;256:327-32.

[34] Hammann S, Kropfl A, Vetter W. More than 170 polyunsaturated tocopherol-related compounds in a vitamin E capsule: Countercurrent chromatographic enrichment, gas chromatography/mass spectrometry analysis and preliminary identification of the potential artefacts. J Chromatogr A. 2016;1476:77-87.

[35] Hammann S, Englert M, Müller M, Vetter W. Accelerated separation of GC-amenable lipid classes in plant oils by countercurrent chromatography in the co-current mode. Anal Bioanal Chem. 2015;407(30):9019-28.

[36] Vetter W, Hammann S, Müller M, Englert M, Huang Y. The use of countercurrent chromatography in the separation of nonpolar lipid compounds. J Chromatogr A. 2017;1501:51-60.

[37] Ito Y. Golden rules and pitfalls in selecting optimum conditions for high-speed counter-current chromatography. J Chromatogr A. 2005; 1065(2):145-68.

[38] Wells RJ. Recent advances in non-silylation derivatization techniques for gas chromatography. J Chromatogr A. 1999;843(1):1-18.

[39] Fiehn O, Kopka J, Dörmann P, Altmann T, Trethewey RN, Willmitzer L. Metabolite profiling for plant functional genomics. Nat Biotechnol. 2000;18(11):1157-61.

[40] Chiew Wei P, Yuen May C, Ah Ngan M, Cheng Hock C. The Effect of Physical Refining on Palm Vitamin E (Tocopherol, Tocotrienol and Tocomonoenol). American Journal of Applied Sciences. 2007;4(6).

[41] Nagy K, Courtet-Compondu MC, Holst B, Kussmann M. Comprehensive analysis of vitamin E constituents in human plasma by liquid chromatography-mass spectrometry. Anal Chem. 2007;79(18):7087-96.

[42] Büsing A, Ternes W. Separation of $\alpha$-tocotrienol oxidation products and eight tocochromanols by HPLC with DAD and fluorescence detection and identification of unknown peaks by DAD, PBI-EIMS, FTIR, and NMR. Anal Bioanal Chem. 2011;401(9):2843-54.

[43] Viñas P, Bravo-Bravo M, López-García I, Pastor-Belda M, Hernández-Córdoba M. Pressurized liquid extraction and dispersive liquidliquid microextraction for determination of tocopherols and tocotrienols in plant foods by liquid chromatography with fluorescence and atmospheric pressure chemical ionization-mass spectrometry detection. Talanta. 2014;119:98-104.

[44] ̌imnáčová L, Hušek P, Šimek P. A new method for immediate derivatization of hydroxyl groups by fluoroalkyl chloroformates and its application for the determination of sterols and tocopherols in human serum and amniotic fluid by gas chromatography-mass spectrometry. J Chromatogr A. 2014;1339:154-67. 
[45] Lanina SA, Toledo P, Sampels S, Kamal-Eldin A, Jastrebova JA. Comparison of reversed-phase liquid chromatography-mass spectrometry with electrospray and atmospheric pressure chemical ionization for analysis of dietary tocopherols. J Chromatogr A. 2007;1157(1):159-70.

[46] Górnaś P, Siger A, Polewski K, Pugajeva I, Waśkiewicz A. Factors affecting tocopherol contents in coffee brews: NP-HPLC/FLD, RP-UPLC-ESI/MSn and spectroscopic study. Eur Food Res Technol. 2014;238(2):259-64.

[47] Grebenstein N, Frank J. Rapid baseline-separation of all eight tocopherols and tocotrienols by reversed-phase liquid-chromatography with a solid-core pentafluorophenyl column and their sensitive quantification in plasma and liver. J Chromatogr A. 2012;1243:39-46.

[48] Turne C, King JW, Mathiasson L. Supercritical fluid extraction and chromatography for fat-soluble vitamin analysis. J Chromatogr A. 2001;936(1-2):215-37.

[49] Méjean M, Brunelle A, Touboul D. Quantification of tocopherols and tocotrienols in soybean oil by supercritical-fluid chromatography coupled to high-resolution mass spectrometry. Anal Bioanal Chem. 2015;407(17):5133-42.

[50] Cunha SC, Amaral JS, Fernandes JO, Oliveira MB. Quantification of tocopherols and tocotrienols in portuguese olive oils using HPLC with three different detection systems. J Agric Food Chem. 2006;54(9):3351-6.

[51] Beppu F, Sakuma A, Kasatani S, Aoki Y, Gotoh N. Application of Partial Hydrogenation for the Generation of Minor Tocochromanol Homologs and Functional Evaluation of Hydrogenated Tocotrienol-rich Vitamin E Oil in Diabetic Obese Mice. J Oleo Sci. 2021;70(1):103-12.

[52] Strohschein S, Rentel C, Lacker T, Bayer E, Albert K. Separation and Identification of Tocotrienol Isomers by HPLC-MS and HPLC-NMR Coupling. Anal Chem. 1999;71(9):1780-5. 